Original Article

\title{
Relationship between stride length and maximal ball velocity in collegiate baseball pitchers
}

\author{
Osamu Yanagisawa, PhD ${ }^{1)^{*}}$, Hidenori TANiguchi, BA ${ }^{1)}$ \\ 1) Faculty of Business Information Sciences, Jobu University: 634-1 Toyaduka-cho, Isesaki, Gunma \\ 372-8588, Japan
}

\begin{abstract}
Purpose] To evaluate the relationship between stride length during a pitch and maximal ball velocity and define the determinants of stride length in collegiate baseball pitchers. [Participants and Methods] Eighteen collegiate baseball pitchers participated in this study. Using a standard tape measure, the distance between each participant's legs was measured after maximal abduction of both hip joints in a standing position. The pitchers threw fastballs on an indoor pitching mound at an official pitching distance. The throwing motion was recorded with four high-speed video cameras $(240 \mathrm{~Hz})$, while the ball velocity was measured using a radar gun. The stride length at foot contact was calculated at the maximal ball velocity using a three-dimensional motion analysis system. [Results] The maximal ball velocity (mean $129.8 \mathrm{~km} / \mathrm{h}$ ) had a significant positive correlation with the absolute stride length during a pitch ( $\mathrm{r}=0.55)$, but no correlation with the relative stride length ( $\%$ body height, $\%$ lower extremity length, and \% maximal open legs' width). Stride length during a pitch did not significantly correlate with the pitcher's body height, lower extremity length, and maximal open legs' width. [Conclusion] A longer stride length contributes to a higher ball velocity in collegiate baseball pitchers.

Key words: Hip function, Biomechanics, Baseball pitching
\end{abstract}

(This article was submitted Apr. 16, 2020, and was accepted Jun. 22, 2020)

\section{INTRODUCTION}

In baseball pitching, stride length is thought to be a significant biomechanical parameter for generating greater translational energy using the downward slope of a pitching mound ${ }^{1-5)}$. Ramsey et al. ${ }^{3)}$ showed that total body linear momentum in an intended throwing direction (toward a home plate) increased with extended stride length. Therefore, it is quite likely that a larger stride length contributes to an increase in ball velocity. In fact, previous studies showed a positive correlation between stride length and ball velocity in professional ${ }^{6)}$ and youth/adolescent ${ }^{7)}$ baseball pitchers. However, van Trigt et al. ${ }^{8)}$ reported no significant relationship between these two variables in youth baseball pitchers. Very few studies have attempted to investigate the direct relationship between ball velocity and stride length in baseball pitchers. Naturally, consensus on the matter has yet to be reached.

Stride length during a pitch may depend on hip flexibility of the pitcher. The hip flexibility of baseball pitchers has been assessed in other reports ${ }^{9-12}$, but the direct relationship between hip flexibility and stride length during a pitch has not been sufficiently investigated. Particularly, hip abduction flexibility of the pitcher may be related to stride length during a pitch because of the similarity to the stride action of baseball pitching. Robb et al. ${ }^{12}$ ) reported a significant, positive correlation between stride length during a pitch and the passive range of motion of hip abduction in the stride leg in professional baseball pitchers. To our knowledge, this was the only published study that compared stride length to hip flexibility. In addition, stride length during a pitch can be closely correlated with pitcher's body height and lower extremity length. However, little is known regarding the determinants of stride length during a pitch in baseball pitchers.

*Corresponding author. Osamu Yanagisawa (E-mail: yanagisawa@ic.jobu.ac.jp)

(C2020 The Society of Physical Therapy Science. Published by IPEC Inc.

(c) (1) $\odot$ This is an open-access article distributed under the terms of the Creative Commons Attribution Non-Commercial No DerivaCC BY NC ND tives (by-nc-nd) License. (CC-BY-NC-ND 4.0: https://creativecommons.org/licenses/by-nc-nd/4.0/) 
This study aimed to evaluate the relationship between stride length during a pitch and maximal ball velocity, and the determinants of stride length in collegiate baseball pitchers. We hypothesized that a longer stride length would lead to a higher ball velocity in baseball pitchers and that stride length during a pitch may depend on a pitcher's body height, lower extremity length, or hip abduction flexibility.

\section{PARTICIPANTS AND METHODS}

Eighteen male collegiate baseball pitchers (mean and standard deviation [SD]; age, $19.4 \pm 1.1$ years; height, $177.4 \pm$ $6.0 \mathrm{~cm}$; weight, $76.8 \pm 6.1 \mathrm{~kg}$ ) participated in the present study immediately after the end of their autumn baseball league games. Of the 18 pitchers, 6 were left-handed. The participants had no pain or discomfort at the time of the measurements and no previous surgical history.

This study was approved by the Ethical Committee of Jobu University (No.17-B01) and conformed to the current Declaration of Helsinki guidelines. Before the measurement, the purpose, potential risks, and examination procedures of this study were explained to all participants. Written informed consent was obtained from each participant, and the participants' rights were fully protected.

After self-stretching of the hip joint, the participants maximally abducted both hip joints in a standing position with the upper body perpendicular to the floor surface (Fig. 1). The distance between both heels was measured once after maximal hip abduction using a standard tape measure. In addition, the length of the pivot lower extremity (on the same side as the throwing arm) was measured from the greater trochanter to the lateral malleolus using a standard tape measure.

After measuring the maximal distance between their open legs, the participants were given an unlimited amount of time to warm up for pitching. The pitchers threw fastballs toward a catcher at maximal effort from a stretch position on a hand-made indoor pitching mound. The distance between a pitching rubber on the mound and a home plate was $18.44 \mathrm{~m}$, which is an official pitching distance. The medial line of the pivot foot was adjusted to the anterior line of the pitching rubber before each pitch so that the starting point was the same for all of the participants. The pitchers were requested to aim at the strike zone (60 cm long $\times 43 \mathrm{~cm}$ wide) of a hand-made apparatus located in front of the home plate. The strike zone of the apparatus corresponded to that of a batter approximately $175 \mathrm{~cm}$ tall. Ball velocities were measured using a radar gun (16JYM10000, MIZUNO Corporation, Osaka, Japan) from behind the catcher. The pitchers continued to pitch until 3 fastballs passed through the strike zone and the maximal ball velocity of the fastballs was used for analysis.

The pitching data were collected using four high-speed video cameras (EX-ZR1600, Casio, Tokyo, Japan) with $240 \mathrm{~Hz}$ frame rates. The cameras were placed at four positions around the pitching mound (front left and right, rear left and right). The cameras were calibrated to perform a three-dimensional motion analysis using a metal reference frame placed on the pitching mound and were not repositioned after set-up (Fig. 2a). The reference frame was $1.8 \mathrm{~m}$ long $\times 1.2 \mathrm{~m}$ wide $\times 1.8 \mathrm{~m}$ high. Before each pitch, a flashlight was used to synchronize the video data from the four cameras. The stride length during a pitch was defined as the distance between the pitching rubber and the heel of the stride leg (on the opposite side of the throwing arm) at the moment of stride foot contact ${ }^{13)}$ (Fig. 2b). A reflective marker was attached to the heel of the stride leg and the stride length when the maximal ball velocity was recorded was calculated using a three-dimensional motion analysis system (ToMoCo-VM, Tousou system, Saitama, Japan). In addition, relative stride length was calculated as a percentage of

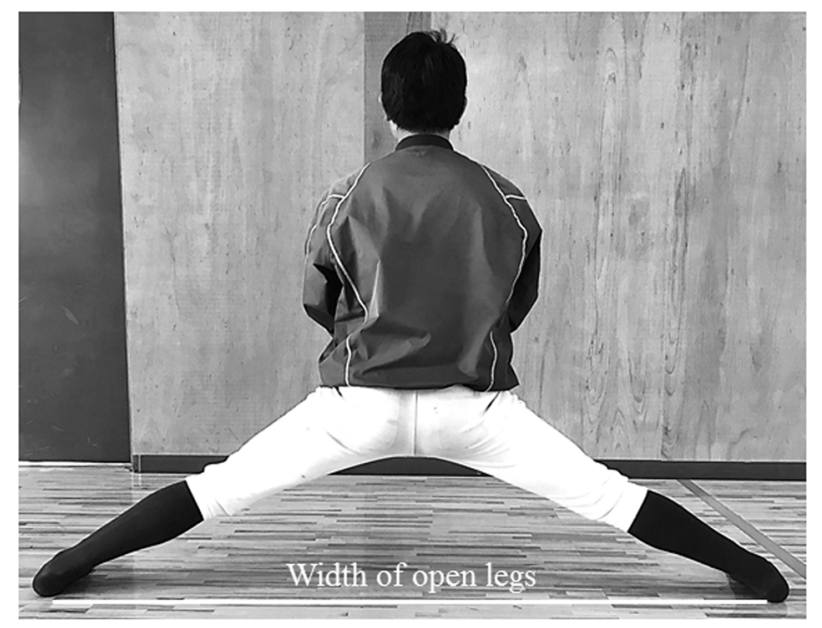

Fig. 1. Measurement of maximal distance between open legs. The distance between both heels was measured using a standard tape measure after the participants maximally abducted both hip joints in a standing position with the upper body perpendicular to the floor surface and with both feet paralleled. 
the participant's body height, lower extremity length, and maximal open legs' width.

The mean \pm SD was calculated for all variables. Pearson's correlation coefficients (r) were used to evaluate the relationships between maximal ball velocity and the absolute/relative values of stride length during a pitch. Similarly, the correlations of stride length with the pitcher's body height, lower extremity length, and maximal open legs' width were also assessed. Positive or negative correlation coefficients were characterized as follows; very weak ( 0 to 0.2 or 0 to -0.2$)$, weak $(0.2$ to 0.4 or -0.2 to -0.4$)$, moderate ( 0.4 to 0.7 or -0.4 to -0.7$)$, strong $(0.7$ to 0.9 or -0.7 to -0.9$)$, and very strong $(0.9$ to 1.0 or -0.9 to -1.0). Statistical analysis was performed with SPSS Statistics (Version 23, IBM Corporation, Armonk, NY, USA). Statistical significance was set at $\mathrm{p}<0.05$ for all analyses.

\section{RESULTS}

The measurement data are summarized in Table 1. A positive correlation was found between maximal ball velocity and the absolute stride length during a pitch $(\mathrm{p}=0.02, \mathrm{r}=0.55)$. However, maximal ball velocity had no significant correlation with the relative stride length ( $\%$ body height, $\mathrm{p}=0.15, \mathrm{r}=0.36 ; \%$ lower extremity length, $\mathrm{p}=0.20, \mathrm{r}=0.32 ; \%$ maximal open legs' width, $\mathrm{p}=0.34, \mathrm{r}=0.24)$. In addition, stride length during a pitch was not significantly correlated with the pitcher's body height $(\mathrm{p}=0.53, \mathrm{r}=0.16)$, lower extremity length $(\mathrm{p}=0.95, \mathrm{r}=-0.02)$, and maximal open legs' width $(\mathrm{p}=0.88, \mathrm{r}=-0.04)$.

\section{DISCUSSION}

As expected, the present study revealed that the absolute stride length at the instant of stride foot contact had a significant, positive, moderate correlation with maximal ball velocity in collegiate baseball pitchers. In professional pitchers, Montgomery and Knudson ${ }^{6}$ ) demonstrated that decreases in stride length lowered ball velocity, whereas increases in stride length increased ball velocity without affecting accuracy. It is possible that a longer stride length increases the total body linear
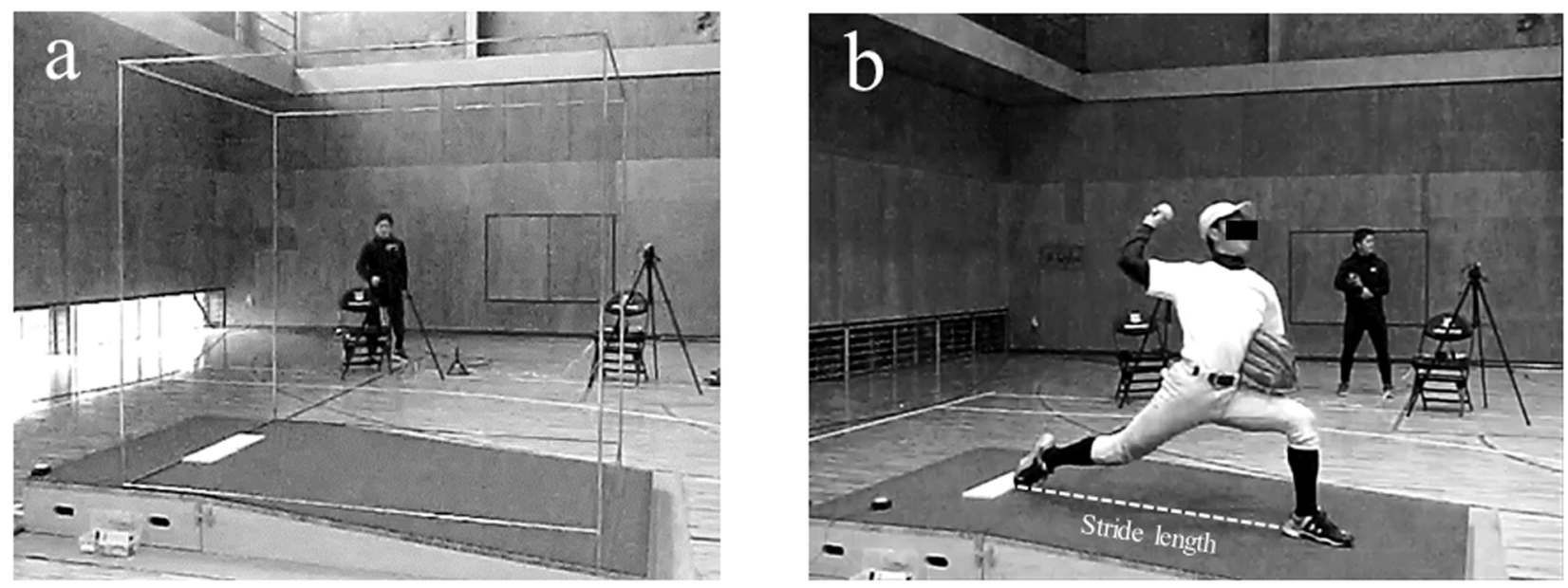

Fig. 2. A metal reference frame on an indoor portable pitching mound (a) and stride length at foot contact during baseball pitching (b). The stride length was calculated as the distance between the pitching rubber and the heel of the stride leg at the instance of stride foot contact.

Table 1. Participant descriptive characteristics

\begin{tabular}{lc}
\hline Body height (cm) & $177.4 \pm 6.0$ \\
Lower extremity length (cm) & $84.3 \pm 3.8$ \\
Maximal width of open legs (cm) & $162.1 \pm 11.6$ \\
Maximal width of open legs (\% Lower extremity length) & $192.3 \pm 12.0$ \\
Stride length (cm) & $129.3 \pm 10.9$ \\
Stride length (\% Body height) & $72.9 \pm 6.3$ \\
Stride length (\% Lower extremity length) & $153.7 \pm 14.7$ \\
Stride length (\% Maximal open legs' width) & $80.2 \pm 8.8$ \\
Maximal ball velocity (km/h) & $129.8 \pm 6.8$ \\
\hline
\end{tabular}

Mean \pm SD. 
momentum, which contributes to a higher ball velocity ${ }^{1-4,6,7)}$. However, a longer stride length may be prone to physical fatigue. Crotin et al. ${ }^{14)}$ showed that compared with a short stride length, a long stride length increased physiological demand, as exemplified by changes in perceived exertion, heart rate, and metabolic responses. Therefore, considering that starting pitchers may throw over 100 pitches in a complete 9-inning baseball game, they may need to strategically adjust their stride length during the course of the game.

In contrast, the relative stride length to body height had no significant correlation with maximal ball velocity in collegiate baseball pitchers. Although Sgroi et al. ${ }^{7}$ revealed a significant positive correlation between maximal ball velocity and stride length (\% body height) in youth and adolescent pitchers, previous studies have shown similar results to the present study. van Trigt et al. ${ }^{8)}$ reported that the relative stride length (\% body height) was not significantly associated with ball velocity in youth baseball pitchers. Dun et al. ${ }^{15)}$ also demonstrated that younger professional baseball pitchers $(<20.4$ years $)$ had a significantly longer relative stride length ( $\%$ body height) than older pitchers ( $>27.0$ years), but there was no difference in ball velocity between the two groups. Moreover, despite showing a significant difference in ball velocity, the relative stride length (\% body height) did not differ between American and Korean professional pitchers ${ }^{16}$ ) or between high- and low-ball-velocity collegiate pitchers ${ }^{17}$. Naturally, baseball pitching is a very complex movement in which many body segments are involved. Therefore, it is clear that kinematic parameters other than stride length also significantly influence ball velocity $7,8,12,16-20$ ). Furthermore, the present study found that the relative stride length to lower extremity length or maximal open legs' width did not significantly correlate with the maximal ball velocity. In short, it is not always the case that the ball velocity becomes higher as the stride length during a pitch gets closer to the pitcher's body height, lower extremity length, or maximal open legs' width. Although a longer stride length plays an important role in generating greater translational energy toward a throwing direction ${ }^{3,4)}$, stride length influences the smooth energy transfer from the pivot leg to the stride leg and trunk, as part of the entire kinetic chain during a pitch ${ }^{1,5,21)}$. Thus, stride length should be long enough for the pitcher to appropriately stretch out the body, but not so long that the pitcher is unable to smoothly shift body weight from the pivot leg to the stride leg and rotate the hips properly ${ }^{1)}$. In individual pitchers, the longest possible stride length that does not disturb the smooth transfer of energy during a pitch should be found.

Contrary to expectations, stride length during a pitch was not significantly correlated with maximal open legs' width. It was reported that stride length during baseball pitching was positively correlated with the passive range of motion of hip abduction in the stride leg in professional baseball pitchers ${ }^{12)}$. In the present study, stride length during a pitch did not demand the maximal range of motion for hip abduction (approximately 80\%, Table 1), and the stride length to maximal open legs' width had relatively large individual differences. These results might lead to no significant correlation between maximal open legs' width and stride length during a pitch.

Stride length as a percentage of body height is an indicator of the ability of the pitcher to take an appropriate stride relative to body height. The average stride length in the present study was approximately $73 \%$ of body height (Table 1), which is comparable to the stride lengths found in studies conducted by Fleisig et al. ${ }^{22)}$ and Keeley et $\mathrm{al}^{23)}$. In fact, stride length during a pitch varies greatly and is independent of age or competitive level (Table 2). As shown in Table 2, the various stride lengths (\% body height) may result, at least partially, from methodological differences, such as a different definition of stride length and pitching conditions. The inclination angle of the pitching mound may also differ between studies. In the present study, stride length during a pitch was not significantly related to the pitcher's body height and lower extremity length. Thus, the relative stride length normalized by these morphological items may have relatively large individual differences.

The present study has some limitations. Although this study evaluated the relationship between maximal open legs' width (hip abduction flexibility) and stride length, hip abduction strength may be important for stabilizing the pelvis and lengthening the stride length by preventing a downward tilt of the contralateral pelvis during the wind-up and early-cocking phases of a baseball pitch ${ }^{9}$. Therefore, the relationship between hip abduction strength and stride length should be fully investigated in the future. Additionally, the participants in this study were all collegiate baseball pitchers and we did not include pitchers at a higher competitive level, e.g. professional pitchers. The small number of participants in this study may also be another limitation. Moreover, all of the participants threw fastballs from a stretch position in this study. Thus, ball velocity may have been slightly lower compared to a pitch from a wind-up position.

In conclusion, the findings of this study suggest that stride length at stride foot contact during a pitch should be as long as possible to increase ball velocity. However, stride length should not be so long that the pitcher is unable to smoothly transfer kinetic energy from the pivot leg to the stride leg and trunk during a pitch. The data of this study would be useful for constructing training, conditioning, and rehabilitation programs for baseball pitchers. However, further research will be required to reduce the discrepancies in data described above by conducting larger trials that include pitchers from different competitive levels.

\section{Funding}

This study was supported by a Grant-in-Aid for Scientific Research from Japan Society for the Promotion of Science under Grant 16K01731.

\section{Conflict of interest}

We have no financial and personal relationship with other people or organization that could inappropriately influence or bias our work. 
Table 2. Comparison of stride length between the present study and the previous studies at various competitive levels

\begin{tabular}{|c|c|c|c|c|c|c|}
\hline & Participants & Age (years) & $\begin{array}{l}\text { Number } \\
\text { of par- } \\
\text { ticipants }\end{array}$ & $\begin{array}{l}\text { Pitching } \\
\text { condition }\end{array}$ & $\begin{array}{l}\text { Definition of stride length during baseball } \\
\text { pitching (at stride foot contact) }\end{array}$ & $\begin{array}{c}\text { Stride } \\
\text { length } \\
\text { (\% body } \\
\text { height) }\end{array}$ \\
\hline $\begin{array}{l}\text { Present } \\
\text { study }\end{array}$ & Collegiate & $19.4 \pm 1.1$ & 18 & $\begin{array}{l}\text { Indoor pitching } \\
\text { mound }\end{array}$ & $\begin{array}{l}\text { The distance between the pitching rubber } \\
\text { and the heel of the stride leg }\end{array}$ & $72.9 \pm 6.3$ \\
\hline $\begin{array}{l}\text { van Trigt } \\
\text { et al. }(2018)\end{array}$ & Youth & $15.2 \pm 1.7$ & 52 & $\begin{array}{l}\text { Indoor pitching } \\
\text { mound }\end{array}$ & $\begin{array}{l}\text { The distance between the pitching rubber } \\
\text { and the ankle joint center of the stride leg }\end{array}$ & $79.8 \pm 6.0$ \\
\hline $\begin{array}{l}\text { Fry et al. } \\
(2017)\end{array}$ & Youth & $10.4 \pm 1.3$ & 92 & $\begin{array}{l}\text { Indoor pitching } \\
\text { mound }\end{array}$ & $\begin{array}{l}\text { The distance between the pitching rubber } \\
\text { and the heel of the stride leg }\end{array}$ & $66.0 \pm 7.1$ \\
\hline \multirow{2}{*}{$\begin{array}{l}\text { Kageyama } \\
\text { et al. (2015) }\end{array}$} & Adolescent & $13.9 \pm 0.6$ & 32 & \multirow{2}{*}{$\begin{array}{l}\text { Indoor pitching } \\
\text { mound }\end{array}$} & \multirow{2}{*}{$\begin{array}{l}\text { The distance between the ankle joint cen- } \\
\text { ters of both legs }\end{array}$} & $82.9 \pm 6.1$ \\
\hline & Collegiate & $19.6 \pm 0.9$ & 30 & & & $84.6 \pm 4.2$ \\
\hline $\begin{array}{l}\text { Keeley et al. } \\
(2015)\end{array}$ & High school & $16.8 \pm 1.4$ & 34 & $\begin{array}{l}\text { Indoor pitching } \\
\text { mound }\end{array}$ & $\begin{array}{l}\text { The distance between the distal region of } \\
\text { the right and left shanks }\end{array}$ & $75.9 \pm 5.3$ \\
\hline $\begin{array}{l}\text { Milewski } \\
\text { et al. (2012) }\end{array}$ & Adolescent & $10.5-14.7$ & 32 & Flat ground & $\begin{array}{c}\text { The distance between the ankle joint cen- } \\
\text { ters of both legs }\end{array}$ & $69 \pm 6$ \\
\hline \multirow{2}{*}{$\begin{array}{l}\text { Dun et al. } \\
(2007)\end{array}$} & \multirow{2}{*}{ Professional } & $19.7 \pm 0.5^{*}$ & 10 & \multirow{2}{*}{$\begin{array}{l}\text { Indoor pitching } \\
\text { mound }\end{array}$} & \multirow{2}{*}{ Undescribed } & $82.5 \pm 4.1$ \\
\hline & & $29.5 \pm 2.0^{* *}$ & 12 & & & $77.3 \pm 5.1$ \\
\hline $\begin{array}{l}\text { Fleisig et al. } \\
(2006)\end{array}$ & Collegiate & $20 \pm 1$ & 21 & $\begin{array}{l}\text { Indoor pitching } \\
\text { mound }\end{array}$ & $\begin{array}{c}\text { The distance between the ankle joint cen- } \\
\text { ters of both legs }\end{array}$ & $70 \pm 4$ \\
\hline \multirow{5}{*}{$\begin{array}{l}\text { Escamilla } \\
\text { et al. }(2002)\end{array}$} & Drofeccional & $22.6 \pm 3.5^{\#}$ & 11 & \multirow{5}{*}{$\begin{array}{l}\text { Indoor pitching } \\
\text { mound }\end{array}$} & \multirow{5}{*}{$\begin{array}{l}\text { The distance between the pitching rubber } \\
\text { and the lateral malleolus of the stride leg }\end{array}$} & $91 \pm 8$ \\
\hline & Protessional & $25.1 \pm 4.1^{\# \#}$ & 8 & & & $85 \pm 5$ \\
\hline & Olympic (Australia) & $24 \pm 3$ & 8 & & & $82 \pm 7$ \\
\hline & Olympic (Italy) & $29 \pm 5$ & 8 & & & $83 \pm 6$ \\
\hline & Olympic (Netherlands) & $28 \pm 6$ & 6 & & & $78 \pm 6$ \\
\hline \multirow{6}{*}{$\begin{array}{l}\text { Escamilla } \\
\text { et al. }(2001)^{\uparrow}\end{array}$} & Olympic (Japan) & $24 \pm 4$ & 6 & \multirow{6}{*}{$\begin{array}{l}\text { Outdoor pitching } \\
\text { mound }\end{array}$} & \multirow{6}{*}{$\begin{array}{l}\text { The distance between the ankle joint cen- } \\
\text { ters of both legs }\end{array}$} & $86 \pm 3$ \\
\hline & Olympic (Korea) & $22 \pm 2$ & 6 & & & $85 \pm 4$ \\
\hline & Olympic (USA) & $21 \pm 1$ & 5 & & & $80 \pm 2$ \\
\hline & Olympic (Cuba) & $26 \pm 2$ & 5 & & & $80 \pm 5$ \\
\hline & Olympic (Nicaragua) & $28 \pm 7$ & 4 & & & $80 \pm 7$ \\
\hline & Youth & $10-15$ & 23 & & & $85 \pm 8$ \\
\hline \multirow{3}{*}{$\begin{array}{l}\text { Fleisig et al. } \\
\text { (1999) }\end{array}$} & High school & $15-20$ & 33 & \multirow{3}{*}{$\begin{array}{l}\text { Indoor pitching } \\
\text { mound }\end{array}$} & \multirow{3}{*}{$\begin{array}{l}\text { The distance between pitching rubber and } \\
\text { the ankle of the stride leg }\end{array}$} & $85 \pm 9$ \\
\hline & Collegiate & $17-23$ & 115 & & & $85 \pm 6$ \\
\hline & Professional & $20-29$ & 60 & & & $86 \pm 5$ \\
\hline
\end{tabular}

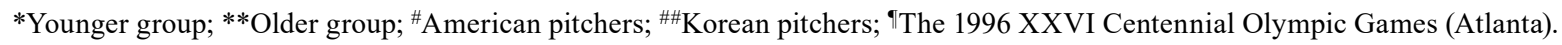

\section{REFERENCES}

1) Dillman CJ, Fleisig GS, Andrews JR: Biomechanics of pitching with emphasis upon shoulder kinematics. J Orthop Sports Phys Ther, 1993 , $18: 402-408$. [Medline] [CrossRef]

2) Fortenbaugh D, Fleisig GS, Andrews JR: Baseball pitching biomechanics in relation to injury risk and performance. Sports Health, 2009, 1: 314-320. [Medline] [CrossRef]

3) Ramsey DK, Crotin RL, White S: Effect of stride length on overarm throwing delivery: a linear momentum response. Hum Mov Sci, 2014, 38: 185-196. [Medline] [CrossRef]

4) Crotin RL, Bhan S, Ramsey DK: An inferential investigation into how stride length influences temporal parameters within the baseball pitching delivery. Hum Mov Sci, 2015, 41: 127-135. [Medline] [CrossRef]

5) Seroyer ST, Nho SJ, Bach BR, et al.: The kinetic chain in overhand pitching: its potential role for performance enhancement and injury prevention. Sports Health, 2010, 2: 135-146. [Medline] [CrossRef]

6) Montgomery J, Knudson D: A method to determine stride length for baseball pitching. Appl Res Coach Athletes, 2002 , 17: 75-84.

7) Sgroi T, Chalmers PN, Riff AJ, et al.: Predictors of throwing velocity in youth and adolescent pitchers. J Shoulder Elbow Surg, 2015, 24: 1339-1345. [Medline] [CrossRef]

8) van Trigt B, Schallig W, van der Graaff E, et al.: Knee angle and stride length in association with ball speed in youth baseball pitchers. Sports Basel, 2018, 6: E51. [Medline] [CrossRef]

9) Laudner KG, Moore SD, Sipes RC, et al.: Functional hip characteristics of baseball pitchers and position players. Am J Sports Med, 2010, 38: 383-387. [Medline] [CrossRef] 
10) McCulloch PC, Patel JK, Ramkumar PN, et al.: Asymmetric hip rotation in professional baseball pitchers. Orthop J Sports Med, 2014, 2: 2325967114521575. [Medline]

11) Sauers EL, Huxel Bliven KC, Johnson MP, et al.: Hip and glenohumeral rotational range of motion in healthy professional baseball pitchers and position players. Am J Sports Med, 2014, 42: 430-436. [Medline] [CrossRef]

12) Robb AJ, Fleisig G, Wilk K, et al.: Passive ranges of motion of the hips and their relationship with pitching biomechanics and ball velocity in professional baseball pitchers. Am J Sports Med, 2010, 38: 2487-2493. [Medline] [CrossRef]

13) Fry KE, Pipkin A, Wittman K, et al.: Youth baseball pitching stride length: normal values and correlation with field testing. Sports Health, 2017, 9: 205-209. [Medline] [CrossRef]

14) Crotin RL, Kozlowski K, Horvath P, et al.: Altered stride length in response to increasing exertion among baseball pitchers. Med Sci Sports Exerc, 2014, 46: 565-571. [Medline] [CrossRef]

15) Dun S, Fleisig GS, Loftice J, et al.: The relationship between age and baseball pitching kinematics in professional baseball pitchers. J Biomech, 2007 , 40 : 265-270. [Medline] [CrossRef]

16) Escamilla R, Fleisig G, Barrentine S, et al.: Kinematic and kinetic comparisons between American and Korean professional baseball pitchers. Sports Biomech, 2002, 1: 213-228. [Medline] [CrossRef]

17) Kageyama M, Sugiyama T, Takai Y, et al.: Kinematic and kinetic profiles of trunk and lower limbs during baseball pitching in collegiate pitchers. J Sports Sci Med, 2014, 13: 742-750. [Medline]

18) Fleisig GS, Barrentine SW, Zheng N, et al.: Kinematic and kinetic comparison of baseball pitching among various levels of development. J Biomech, 1999, 32: 1371-1375. [Medline] [CrossRef]

19) Escamilla RF, Fleisig GS, Zheng N, et al.: Kinematic comparisons of 1996 Olympic baseball pitchers. J Sports Sci, 2001, 19: 665-676. [Medline] [CrossRef]

20) Kageyama M, Sugiyama T, Kanehisa H, et al.: Difference between adolescent and collegiate baseball pitchers in the kinematics and kinetics of the lower limbs and trunk during pitching motion. J Sports Sci Med, 2015, 14: 246-255. [Medline]

21) Milewski MD, Õunpuu S, Solomito M, et al.: Adolescent baseball pitching technique: lower extremity biomechanical analysis. J Appl Biomech, 2012, 28: 491-501. [Medline] [CrossRef]

22) Fleisig GS, Kingsley DS, Loftice JW, et al.: Kinetic comparison among the fastball, curveball, change-up, and slider in collegiate baseball pitchers. Am J Sports Med, 2006, 34: 423-430. [Medline] [CrossRef]

23) Keeley DW, Oliver GD, Dougherty CP, et al.: Lower body predictors of glenohumeral compressive force in high school baseball pitchers. J Appl Biomech, 2015, 31: 181-188. [Medline] [CrossRef] 